\title{
Guest editorial: characterisation of crack tip fields
}

Joint Special Issues of the International Fournal of Fatigue (Elsevier) and Fatigue \& Fracture of Engineering Materials \& Structures (Wiley) containing the fully peer reviewed proceedings of the 2nd International Conference on Characterisation of Crack Tip Stress Fields held in Malaga, Spain over 15-17 April 2013.

The advent of full-field experimental techniques capable of measuring crack tip fields across a range of size scales has led to considerable activity on characterisation of crack and notch tip fields. As noted in the Guest Editorial of the Joint Special Issue of the International Fournal of Fatigue and Fatigue \& Fracture of Engineering Materials \& Structures published after the 1st International Conference held in Forni di Sopra, Italy, in January 2011, there is a growing research consensus that single parameter fracture mechanics approaches have limitations particularly in dealing with crack growth phenomena arising from crack tip shielding. Influences of any plastic enclave on crack tip fields ahead of the crack are maximised during cyclic loading. In the case of a parameter like the stress intensity factor, $K$, which characterises the crack tip field via an elastic approximation, it is not surprising that any set of plasticity-induced circumstances that perturb the assumed crack tip field leads to predictive difficulties.

Modern experimental techniques for measuring displacement, strain and stress, for example, digital image correlation (DIC), electronic speckle pattern interferometry and thermography, coupled with the development of innovative techniques to identify and measure zones of plastic deformation, often using scanning electron microscope techniques, for example, electronic back scatter diffraction $(\mathrm{EBSD})^{1}$ or Fourier transform of backscattered electron images, ${ }^{2}$ have opened up new possibilities for an enhanced understanding of crack tip fields and their influences on crack growth from the microscale, using in situ tensile stages in an SEM, through mesoscale to macroscale.

This second Malaga conference was organised by the University of Malaga with assistance from the Spanish and Italian Fracture Groups. It followed the successful format of the first conference, based around a largely invited group of delegates, and allowing sufficient time for useful discussion after each paper and again at the end of the conference. Summarising the outcomes from this discussion, a number of useful approaches are emerging, which combine detailed experimental crack field observations with theoretical advances. Areas for fruitful future discussion centre on the underlying philosophies, which are the source of many of the remaining controversies.
These various approaches include elastic stress analysis, elastoplastic, and elastic at the plastic boundary. Many are attempts at refined stress intensity parameter approaches, but there are also dislocation-based models and mechanics models. The differences among them are largely related to scale, to scale-mechanism interactions and to the difficulties associated with real microstructures and multiaxiality of loading. It was felt by delegates that further progress would benefit from multi-technique research partnerships, and it was proposed to extend the conference delegate list to include appropriate representation from researchers interested in the following:

- synchrotron micro-diffraction measurements (tomography, near-tip residual stresses)

- DIC

- EBSD

- numerical modelling

- improved analytical understanding

The next conference in the Characterisation of Crack Tip Fields series is proposed to take place in April or early May 2015, probably in Italy, and information will be circulated about this in good time.

The guest editors hope that this fully peer reviewed overview of current thinking in the area of crack tip fields in relation to fatigue and fracture is of use to the research community.

Guest Editors: International Journal of Fatigue

M. N. James, University of Plymouth, UK L. Susmel, University of Sheffield, UK (Workshop Secretariat) F. Iacoviello, University of Cassino, Italy

Guest Editors: FFEMS

Y. Hong, Chinese Academy of Sciences, China E. A. Patterson, University of Liverpool, UK P. Lopez-Crespo, University of Malaga, Spain

(Workshop Secretariat)

\section{REFERENCES}

1 Wright, S. I., Nowell, M. M. and Field, D. P. (2011) A review of strain analysis using electron backscatter diffraction. Microsc. Microanal. 17, 316-329.

2 Yang, Y., Crimp, M., Tomlinson, R. A. and Patterson, E. A. (2012) Quantitative measurement of plastic strain field at a fatigue crack tip. Proc. Roy. Soc. A 468, 2399-2415. 